\title{
Editorial
}

\section{Sustainable Energy Systems: Optimization and Efficiency}

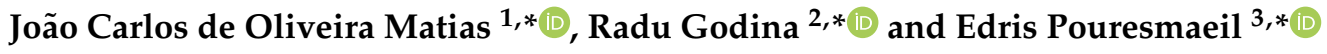 \\ 1 GOVCOPP Research Unit, Department of Economics, Management, Industrial Engineering \\ and Tourism (DEGEIT), University of Aveiro, 3810-193 Aveiro, Portugal \\ 2 UNIDEMI, Department of Mechanical and Industrial Engineering, Faculty of Science and Technology (FCT), \\ Universidade NOVA de Lisboa, 2829-516 Caparica, Portugal \\ 3 Department of Electrical Engineering and Automation, Aalto University, Office 3563, Maarintie 8, \\ 02150 Espoo, Finland \\ * Correspondence: jmatias@ua.pt (J.C.d.O.M.); r.godina@fct.unl.pt (R.G.); edris.pouresmaeil@aalto.fi (E.P.)
}

Received: 3 May 2020; Accepted: 4 June 2020; Published: 26 June 2020

check for updates

\begin{abstract}
The world population is growing at a very high rate, which also entails a massive increase in energy consumption, and also, therefore, in its production, which is gradually and steadily increasing. Energy and the environment are essential to achieving sustainable development, and constitute a fundamental part of human activity. If we consider energy efficiency as the use of an appliance, process or installation for which we try to produce more energy, but with less energy consumption than the average for these appliances, processes or installations, then achieving a higher energy efficiency is imperative. Energy efficiency is a cornerstone policy on the road to stopping climate change and to achieving sustainable societies, along with the development of renewable energy and an environmentally friendly transport policy. In this Special Issue, 11 selected and peer-reviewed articles have been contributed, on a wide range of topics under the umbrella of sustainable energy systems. The published articles encompass distinct areas of interest. One area addresses distributed generation, which addresses such topics as the optimal planning of distributed generation, protection of blind areas in distribution networks, multi-objective optimization in distributed generation, energy management of virtual power plants in distributed generation, and the impact of demand-response programs on a home microgrid, as well as concentrating solar power into a highly renewable, penetrated power system. The second section of the Special Issue addresses a wide range of topics, from parametric studies of $2 \mathrm{MW}$ gas engines or data centers, to combustion characteristics of a non-premixed oxy-flame, to new techniques of PV Tracking, to applications of nanofluids in the thermal performance enhancement of parabolic trough solar collectors.
\end{abstract}

Keywords: sustainable energy systems; energy optimization; renewable energy; distributed generation; energy efficiency; energy policy; multi-energy systems; power generation and systems; electric and hydrogen mobility; building and home energy management; entransy and exergy analyses; fuels; energy

\section{Introduction}

Renewable energy resources have never been more significant than they are today. As more and more environmental and ecological problems have arisen, the use of renewable resources has become the most important step in addressing and overcoming such challenges. Among the actions that can be taken is the use of renewable energy sources [1]. Renewable sources use natural resources, considered inexhaustible because of their ability to regenerate [2]. 
One of the most important challenges of present times is energy efficiency related to consumption and use [3], which encompasses efficiency in energy systems and supply, as well as the demand for final energy [4]. This will maximize the benefits of exploiting the available clean and endogenous primary energy sources [5]. Thus, the technological advances and the new economic frameworks of the energy sector could guarantee full compliance with environmental constraints [6].

In the specific field of energy services, notably electricity, a wide and growing range of opportunities regarding energy efficiency are still on the table. The importance of the greater efficiency of the electrical system should be emphasized. Many technologies and solutions for energy efficiency are readily available and economically viable. However, several barriers still obstruct the application of these technologies, and prevent them from achieving their potential for greater energy efficiency, such as renewable energy uncertainty derived from the variability of power generation [7].

Innovative methods of modelling, which could overcome physical and technical boundary conditions, and at the same time take into consideration economic, environmental and social aspects, could be developed. Therefore, researchers contributed with their manuscripts to this Special Issue, and contribute models, proposals, reviews, and studies. In this Special Issue, 11 selected and peer-reviewed papers were contributed on a wide range of topics, encompassing sustainable energy systems and energy efficiency in processes and systems.

A key share of the electricity produced presently worldwide is still generated by centralized systems, based on conventional fossil fuel plants or nuclear power. The challenges that researchers, policy makers and engineers face in the operation and regulation of traditional power plants, and the development of low voltage power generation systems, have facilitated the surge in distinct opportunities for energy generation, closer to the load, by the consumers themselves, that is, distributed generation (DG) [8-10]. Thus, regarding this topic, several papers are published in this Issue.

In [11], the authors present a simplified analytical approach to optimal planning of DG in electrical distribution networks. Distinct parameters of DG were taken into account and evaluated, in order to achieve a high loss reduction in the electrical distribution networks. The authors concluded that the proposed approach could provide an adequate solution, through a simple algorithm, without resorting to an intensive process of power flow computation.

A multi-objective optimization of accommodation capacity for distributed generation, based on a mixed-strategy Nash equilibrium, considering distribution network flexibility, was presented in [12]. In this publication, a comprehensive learning particle swarm optimization (CLPSO) algorithm is employed to solve this multi-objective optimization model, and it is applied in a real example of a Chinese distribution network. Through this model, while taking into account multiple objectives, the authors reach the optimal solution.

In [13], an energy management scheme for virtual power plants is proposed by considering DG sizing and pricing. In this study, the effect on simulations of distinct types of DG units was considered. The simulations are performed for three cases, and compared using the software HOMER in order to validate the capability of the proposed model. Meanwhile, in [14], the authors present a study addressing the incorporation of concentrated solar power into a highly renewables-penetrated power system, through chance-constrained stochastic unit commitment analysis. The results of this study show a reliable economic value of the concentrating of solar power stations on the improvement of unit commitment schedules. Finally, in [15]s the authors propose a study addressing the impact of demand-response programs on reducing the emissions and cost of a neighborhood home microgrid. Since several generation units are present, the Taguchi orthogonal array testing (TOAT) method was used. The results showed an increase in profits and a decrease in emissions if the proposed algorithm is used.

Still on the topic of DG, protection relay issues are addressed in a study that focuses on the impact of recloser on protecting the blind areas of distribution networks in the presence of DG [16]. In this study, the simulations are made with the help of DIgSILENT software. The case study is based on realistic data of a distribution network, in which the DG comprises two generators with a capacity 
of $4 \mathrm{MW}$. The authors show that with this strategy, the protection of blind areas was achieved by the recloser relay, which improves the distribution network's reliability.

As mentioned in the Abstract, the second section of the Special Issue addresses a wide range of topics. Since solar irradiation is intermittent and suffers from swift fluctuations [17], a PV Tracking design methodology based on an orientation efficiency chart is presented in [18], which, according to the authors, by being based on an orientation efficiency chart, can be applied to the construction or control of other types of solar tracker systems.

Two parametric studies were published in this issue. A thermoeconomic modelling and parametric study of a simple orc, for the recovery of waste heat from a $2 \mathrm{MW}$ gas engine under different working fluids, was presented in [19], and a parametric numerical study of the airflow and thermal performance of a real data center, for improving sustainability by reducing the thermal load [20]. The predictions and analysis of the combustion characteristics of a non-premixed oxy-flame, by applying a hybrid filtered Eulerian stochastic field/flamelet progress variable approach, was addressed in [21]. Comparisons with experimental data, in terms of temperature, scalar distributions and scatter plots, were made, and satisfactory results were obtained.

Finally, in this Issue a review of the state of the art was made regarding the application of nanofluids in the thermal performance enhancement of a parabolic trough solar collector [22], in which the authors stress that an increase in the amount of nanoparticles in nanofluids can lead to higher exergy and thermal efficiency.

Even though many challenges still remain, research and technology are vital tools for reaching a new energy paradigm, which is heading towards responsible and careful use of the environment. Energy efficiency and responsible management can be achieved at any level and in almost any system, as can be seen in the contributions to this Special Issue. For instance, by monitoring consumption, the necessary information is obtained for changing habits and increasing savings and efficiency. Therefore, with small incremental steps, the objective becomes strengthening the role of innovation, with the aim of facing the challenges of climate change with efficient responses that, additionally, can assure an economical, reliable and sustainable energy supply.

Funding: This research received no external funding.

Acknowledgments: This Special Issue is the result of the contributions of various talented authors, experienced reviewers, and the devoted editorial team of Applied Sciences. Thanks are due to all authors and peer reviewers. Finally, the editorial team of Applied Sciences Energy Section are to be congratulated for the success of this project, and in particular, thanks are due to Felicia Zhang, Louise Liu and Daria, as well as to Tamia Qing, Assistant Editor from MDPI Branch Office, Beijing.

Conflicts of Interest: The authors declare no conflict of interest.

\section{References}

1. Saidi, K.; Omri, A. The impact of renewable energy on carbon emissions and economic growth in 15 major renewable energy-consuming countries. Environ. Res. 2020, 186, 109567. [CrossRef] [PubMed]

2. Gozgor, G.; Mahalik, M.K.; Demir, E.; Padhan, H. The impact of economic globalization on renewable energy in the OECD countries. Energy Policy 2020, 139, 111365. [CrossRef]

3. Rodrigues, E.M.G.; Godina, R.; Shafie-khah, M.; Catalão, J.P.S. Experimental Results on a Wireless Wattmeter Device for the Integration in Home Energy Management Systems. Energies 2017, 10, 398. [CrossRef]

4. Oprea, S.-V.; Bâra, A.; Reveiu, A. Informatics Solution for Energy Efficiency Improvement and Consumption Management of Householders. Energies 2018, 11, 138. [CrossRef]

5. Aniello, G.; Többen, J.; Kuckshinrichs, W. The Transition to Renewable Energy Technologies-Impact on Economic Performance of North Rhine-Westphalia. Appl. Sci. 2019, 9, 3783. [CrossRef]

6. Sechilariu, M. Intelligent Energy Management of Electrical Power Systems. Appl. Sci. 2020, 10, 2951. [CrossRef]

7. Tavakkoli, M.; Adabi, J.; Zabihi, S.; Godina, R.; Pouresmaeil, E. Reserve Allocation of Photovoltaic Systems to Improve Frequency Stability in Hybrid Power Systems. Energies 2018, 11, 2583. [CrossRef] 
8. Najafi, A.; Marzband, M.; Mohamadi-Ivatloo, B.; Contreras, J.; Pourakbari-Kasmaei, M.; Lehtonen, M.; Godina, R. Uncertainty-Based Models for Optimal Management of Energy Hubs Considering Demand Response. Energies 2019, 12, 1413. [CrossRef]

9. Tavakkoli, M.; Pouresmaeil, E.; Godina, R.; Vechiu, I.; Catalão, J.P.S. Optimal Management of an Energy Storage Unit in a PV-Based Microgrid Integrating Uncertainty and Risk. Appl. Sci. 2019, 9, 169. [CrossRef]

10. Martínez, S.D.; Campos, F.A.; Villar, J.; Rivier, M. An equilibrium approach for modeling centralized and behind-the-meter distributed generation expansion. Electr. Power Syst. Res. 2020, 184, 106337. [CrossRef]

11. Sa'ed, J.A.; Amer, M.; Bodair, A.; Baransi, A.; Favuzza, S.; Zizzo, G. A Simplified Analytical Approach for Optimal Planning of Distributed Generation in Electrical Distribution Networks. Appl. Sci. 2019, 9, 5446. [CrossRef]

12. Liu, W.; Wu, J.; Wang, F.; Huang, Y.; Dai, Q.; Yang, L. Multi-objective Optimization of Accommodation Capacity for Distributed Generation Based on Mixed Strategy Nash Equilibrium, Considering Distribution Network Flexibility. Appl. Sci. 2019, 9, 4395. [CrossRef]

13. Maanavi, M.; Najafi, A.; Godina, R.; Mahmoudian, M.M.G.; Rodrigues, E. Energy Management of Virtual Power Plant Considering Distributed Generation Sizing and Pricing. Appl. Sci. 2019, 9, 2817. [CrossRef]

14. Gao, S.; Zhang, Y.; Liu, Y. Incorporating Concentrating Solar Power into High Renewables Penetrated Power System: A Chance-Constrained Stochastic Unit Commitment Analysis. Appl. Sci. 2019, 9, 2340. [CrossRef]

15. Fouladfar, M.H.; Loni, A.; Bagheri Tookanlou, M.; Marzband, M.; Godina, R.; Al-Sumaiti, A.; Pouresmaeil, E. The Impact of Demand Response Programs on Reducing the Emissions and Cost of a Neighborhood Home Microgrid. Appl. Sci. 2019, 9, 2097. [CrossRef]

16. Sahebkar Farkhani, J.; Najafi, A.; Zareein, M.; Godina, R.M.G.; Rodrigues, E. Impact of Recloser on Protecting Blind Areas of Distribution Network in the Presence of Distributed Generation. Appl. Sci. 2019, 9, 5092. [CrossRef]

17. Dev, S.; AlSkaif, T.; Hossari, M.; Godina, R.; Louwen, A.; van Sark, W. Solar Irradiance Forecasting Using Triple Exponential Smoothing. In Proceedings of the 2018 International Conference on Smart Energy Systems and Technologies (SEST), Sevilla, Spain, 10-12 September 2018; pp. 1-6.

18. Ruelas, J.; Muñoz, F.; Lucero, B.; Palomares, J. PV Tracking Design Methodology Based on an Orientation Efficiency Chart. Appl. Sci. 2019, 9, 894. [CrossRef]

19. Ochoa, G.V.; Peñaloza, C.A.; Rojas, J.P. Thermoeconomic Modelling and Parametric Study of a Simple ORC for the Recovery of Waste Heat in a 2 MW Gas Engine under Different Working Fluids. Appl. Sci. 2019, 9, 4526. [CrossRef]

20. Macedo, D.; Godina, R.; Dinis Gaspar, P.; da Silva, P.D.; Trigueiros Covas, M. A Parametric Numerical Study of the Airflow and Thermal Performance in a Real Data Center for Improving Sustainability. Appl. Sci. 2019, 9, 3850. [CrossRef]

21. Mahmoud, R.; Jangi, M.; Ries, F.; Fiorina, B.; Janicka, J.; Sadiki, A. Combustion Characteristics of a Non-Premixed Oxy-Flame Applying a Hybrid Filtered Eulerian Stochastic Field/Flamelet Progress Variable Approach. Appl. Sci. 2019, 9, 1320. [CrossRef]

22. Olia, H.; Torabi, M.; Bahiraei, M.; Ahmadi, M.H.; Goodarzi, M.; Safaei, M.R. Application of Nanofluids in Thermal Performance Enhancement of Parabolic Trough Solar Collector: State-of-the-Art. Appl. Sci. 2019, 9, 463. [CrossRef]

(C) 2020 by the authors. Licensee MDPI, Basel, Switzerland. This article is an open access article distributed under the terms and conditions of the Creative Commons Attribution (CC BY) license (http://creativecommons.org/licenses/by/4.0/). 